\title{
ALIGNMENT OF BUSINESS AND INFORMATION STRATEGIES AND ITS IMPACT ON BUSINESS PERFORMANCE
}

\author{
Björn JOHANSSON ${ }^{1}$, František SUDZINA ${ }^{2}$, Andreja PUCIHAR ${ }^{3}$ \\ ${ }^{1}$ Department of Informatics, School of Economics and Management, \\ Lund University, Ole Römers väg 6, 22363 Lund, Sweden \\ ${ }^{2}$ Department of Business and Management, Faculty of Social Sciences \\ and Faculty of Engineering and Science, Aalborg University, \\ Fibigerstrcede 11, 9220 Aalborg, Denmark \\ ${ }^{3}$ Information Systems Department, Faculty of Organizational Sciences, \\ University of Maribor, Kidričeva cesta 55a, 4000 Kranj, Slovenia \\ E-mails: ${ }^{1}$ bjorn.johansson@ics.lu.se; ${ }^{2}$ sudzina@business.aau.dk (corresponding author); \\ 3andreja.pucihar@fov.uni-mb.si
}

Received 17 September 2012; accepted 12 November 2012

\begin{abstract}
Alignment between business strategy and information strategy has been focused on for several years with research suggesting different explanations to how this alignment influences a firm's performance. This article presents results from an investigation of firms in Slovenia about how business people perceived their business strategy and information strategy to be aligned. Respondents' statements from the questionnaire survey on their perceived alignment between business strategy and information strategy were checked against the firms' revenue growth. The analysis of perceived alignment between business strategy, information strategy, and revenue growth shows that there is a significant relationship between alignment and revenue growth in Slovenia, and this link is positive. Managers should aim to align business and information strategies in order to achieve better business performance.
\end{abstract}

Keywords: information systems, empirical research, business strategy, information strategy, alignment, business performance.

JEL Classification: L25, M15.

\section{Introduction}

There has been a great deal of research on the relation between business processes and information strategies (Luftman et al. 2006), focusing on alignment and how it improves business performance. While some studies provide primary anecdotal evidence, e.g. (Plomp, Batenburg 2009; Smits et al. 2009), others (Chan et al. 2006) claim more substantial evidence. Our research question is motivated by Renaud and Kalika's (2008) statement. What the authors propose is that it is not the co-alignment in itself that is a performance factor; rather, it is firms' ability to mediate between alignment and non- 
alignment, as well as between their strategy and their structure, that is of primary importance. This statement could be interpreted that even lack of alignment (in our study this is described as bad alignment of business and information strategies) could lead to a good performance. However, Tallon (2007) and a majority of the papers discussed in the literature review section presents the argument that alignment is a driver for business performance. In relation to Renaud and Kalika, Tallon's work suggests a positive relationship between alignment and perceived IT business value. From this discussion of the different explanations on how alignment influences firms' performance, we have formulated the following research question: Does alignment of business and information strategies have an impact on firms' revenue development? If so, is the influence of alignment positive or negative?

This research explores the views of Renaud and Kalika (2008), as well as that of Tallon (2007), and from the empirical data we investigate whether alignment between business strategies and information strategies influences firms' business performance. The conceptual reason for the need of the investigation is also, as Marchand and Raymond (2008) put it, the fact that the notion of "strategic alignment" is crucial in explaining the performance outcomes of information systems, is not as evident in the conceptualization of enterprise information systems. This is in contrast to a performance measurement system conceptually based on a performance measurement framework that is ideally aligned with a company's business model and performance information needs. Of course, we acknowledge that organizational (e.g., trust/mistrust (Allen, Wilson 2003)) and environmental factors (e.g., environmental uncertainty (Aldrich 1979; Dess, Beard 1984)) have a potential to strengthen or weaken the effects of alignment on firms' performance. In order to explain whether alignment of business and information strategies has an impact on firms' business performance, and whether it is positive or negative, we analyze a data set containing data on perceived alignment and revenue development from 131 firms operating in Slovenia.

The rest of the article is organized as follows. The next section provides a short overview of alignment research with the aim of defining how the term alignment will be used in the article. The second section describes the data sample and the methodology used. The third section reports the results from the analysis of the data. The final section offers conclusions and implications for future research.

\section{A literature review on alignment}

Alignment of IT has been in focus for a long time. Tallon et al. (2001) claim that alignment as strategic alignment between IT and business strategy has been consistently ranked as the single most important issue facing business and IT executives. The survey presented by Luftman et al. (2009) supports this claim made by Tallon et al. (2001), pointing to the fact that IT and business alignment is still a top management concern. However, Luftman et al. (2009) give four reasons why it continues to be elusive: 1) alignment is treated as a "buzz word" resulting in executives discussing it with a lot of different meanings, 2) executives tend to look for the one silver bullet that will 
solve the alignment problem, 3 ) the focus is wrongly placed on how IT is aligned with business, instead of focusing on how IT and business are aligned to each other, and 4) there is a need to go beyond the strong focus on IT infrastructure. With regards to the third point, according to Salmela and Spil (2002), there are several schools of thought: information strategy supporting business strategy (e.g., Papp 1999), synchronization of information and business strategies (e.g., Prahalad, Krishnan 2002), convergence of information and business strategies (e.g., Johnson, Lederer 2005), etc. This discussion implies that there is an interest in alignment and, more importantly, a need to more clearly describe and define alignment.

Chan and Reich (2007) have extensively reviewed the literature on alignment, culminating in the following dimensions of alignment: strategic, structural, social, and cultural. Strategic alignment is the degree to which the business strategy and business plans, and the IT strategy and plans, complement each other. Structural fit between IT and the business constitutes structural alignment. According to Chan (2002), it incorporates the location of IT decision-making rights, reporting relationships, (de)centralization of IT, and the deployment of IT personnel. The social dimension refers to the level that business and IT executives within an organizational unit understand and are committed to the business and to the IT mission, objectives, and plans (Reich, Benbasat 2000). The cultural dimension incorporates elements such as the business planning style and the top management communication style. This paper focuses on the strategic dimension of alignment. Even though strategic alignment is the dimension most often said to influence performance (Henderson, Venkatraman 1993), Simonsen (2007) emphases the operational alignment between business needs and IT solutions, claiming that how top management perceives business values to be gained from IT solutions is of primary importance for how they see alignment being fulfilled.

Henderson and Venkatraman (1993) describe strategic alignment from the point of view of two building blocks. The first is functional integration that is used to label strategic integration and is seen as the link between business strategy and IT strategy. The second is strategic fit, also termed as operational integration, and consists of the link between organizational infrastructure and IT infrastructure. This distinction could be related to the fourth problem with IT alignment to which Luftman et al. (2009) refer, and it could be that a lot of focus from executives is on the strategic fit and not on how IT and business are aligned to each other. It is also possible that the strategic fit is seen as structural alignment (defined by the level of (de)centralization of IT, reporting relationships, location of IT decision-making rights, and the deployment of IT personnel).

However, Chan and Reich (2007) claim that both strategic and structural alignment influence performance. Critics of alignment research argue that since strategy is not a clear concept, as it is also influenced by turbulent unpredictable circumstances, alignment does not succeed (Vitale et al. 1986). There are actually at least three different types of situations that are more problematic when trying to align IT with business strategy. The first is when a firm tries to align IT with business strategy that is not internally consistent, resulting in misalignment. The second is when the innovation in the firm reaches stagnation, and if alignment then takes place, this also results in IT stagnation. 
The third is when a firm is becoming more globalized, culminating in special scale and cultural difficulties for alignment showing up (Chan, Reich 2007).

Chan and Reich (2007) point out that alignment has been conceptualized in various ways; however, most definitions state that alignment is the degree to which the mission, objectives, and plans contained in the business strategy are shared and supported by the IT strategy. This agrees with the definition that Henderson and Venkatraman (1993) give when they define alignment as: the degree of fit and integration among business strategy, IT strategy, business infrastructure, and IT infrastructure. Tallon (2007) proposes that alignment is not just about having a "tight" fit. Instead, it should be understood as aiming to achieve the "right" fit between a specific mix of processes and activities comprising the business strategy. This is in line with what Luftman et al. (2009) emphasize - that alignment needs to focus on how IT and business are aligned to each other.

Two recent research surveys conducted in the Netherlands (Plomp, Batenburg 2009; Smits et al. 2009) also support the notion of positive relationships between alignment of business and information strategies (although it is necessary to point out that the sample size was rather limited). The first researchers, Plomp and Batenburg (2009), investigated the impact of procurement maturity, as well as that of alignment of IT and procurement processes, on procurement performance on a sample of three hospitals. The second researches (Smits et al. 2009) stressed information quality; in their model, strategic alignment impacts information quality, which then impacts business process performance. Their research was conducted in nine organizations.

On a larger sample, Kearns and Sabherwal (2006) modelled the influence of alignment of business and information strategies on business impact of IT through quality of IT project planning and implementation problem in IT projects. They found out that alignment of business and information strategies was positively linked with quality of IT planning and negatively linked with implementation problems in IT projects; quality of IT planning had a positive effect, and implementation problems in IT projects had a negatively effect on business impact of IT.

In this context also the study by Leidner et al. (2011) is of interest. They claim that IS strategy is of high importance for getting the potential value out of IS for organizations. In order to investigate this statement they investigated the importance of having a clearly defined versus an undefined IS strategy and its influence on business performance. Their conclusion is that organizations with a clearly defined IS strategy perform better than organizations with an undefined IS strategy. However, they did not investigate the alignment between IS strategy and business strategy as such, even if the typology of IS strategy they used indirectly focus on alignment. The typology of IS strategies that they investigated was innovative, conservative and undefined IS strategy. In this context it can be said that the undefined IS strategy could be seen as having lack of alignment. Two other studies analysed the impact of structure of IT projects and solutions on productivity and economic performance on large sample of 14.000 EU companies (Dorčák, Delina 2011; Delina, Tkáč 2010). These authors confirmed positive influence of particular structure of IT solutions on general economic performance and pointed to the fact 
that investments into these projects have to be directed at some of the high-effective tools, not at complex solutions.

In addition, Renaud and Kalika (2008) posit that a consensus does exist - both in literature and in practice - that alignment between IS structure and/or strategy and business strategy impacts performance positive. However, in their investigation they did not find support for this, instead, it was found that the more important the firms' prospecting characteristics are, the less alignment impacts firms' performance. Singh and Woo (2009) claim that organizations which have successfully aligned their business strategy with their IT strategy have better performance, compared to organizations which have not managed to align their strategies. However, they add that if alignment is so easy and trivial, it is strange that it has been CIO's top concern for such a long time and that it still attracts considerable attention from researchers. One reason for why alignment have been and still is in focus is presented by Valorinta (2011), who claims that alignment is an on-going organizational process that requires a lot from the ones involved, especially if the alignment should be successful. With this statement, Valorinta more or less adds to the understanding that alignment enhances good business performance.

Chan and Reich (2007) describe three different directions on alignment research: 1) alignment of the business plan and IT plan, 2) examining the fit between business needs and information systems priorities, and 3) alignment and thereby ensuring congruence between the business strategy and IT strategy. The research reported in this paper deals with the last described direction, which, at least according to Luftman et al. (2009), would be a fruitful focus when doing future research on alignment. The next section describes the sample and the methodology used in the study to investigate whether alignment of business and information strategies has an impact on firms' business performance, and whether the influence on alignment is positive or negative.

\section{Data and methodology}

This exploratory paper is based on a questionnaire survey conducted in Slovenia in May and June of 2007. Questionnaire forms accompanied by cover letters were mailed to randomly selected companies. Lists of addresses and information on the number of employees were retrieved from the National Statistical Bureau. With regards to the random sample, 600 questionnaires were sent to small enterprises, 300 to medium enterprises, and 300 to large companies. The definition of company size we used stipulates that companies with 10 to 49 employees are considered small, those with 50 to 249 employees medium-sized enterprises, and those having 250+ employees large companies. This definition is consistent with the European Commission (2003) definition of SMEs, according to which there were 27 small, 36 medium, and 68 large companies in the research sample.

The number of questionnaires mailed to small companies was double that sent to medium and large companies because small companies constituted the highest proportion of companies, and based on our personal experience, they would be less likely to respond. In total, there were 131 responses of 1200 mailings, i.e., a response rate of 
$10.9 \%$. The response rate of $10.9 \%$ is not so low for a paper-based questionnaire survey, and as Armstrong and Overton (1977) illustrate, even a response rate of $80 \%$ may lead to biased estimates. The sample size, the response rate, and the research methodology presented in this paper are comparable to those in Johansson and Sudzina's (2009) study involving Slovak companies. Altogether, 47 chief information officers, 27 chief executive officers, 15 IT managers, 6 accounting officers, 6 managers, 4 chief financial officers, and 26 other employees participated in this research.

In order to answer the research question of whether the alignment of business and information strategies matters when it comes to firms' business performance, we investigated the relationship between perceived alignment and revenue development. In order to avoid the possible effect of variable returns to scale, we included company size as a control variable in the model. Although we acknowledge that diversifying entrants have a performance advantage in comparison with entrepreneurial start-ups, we do not examine this difference in our research explicitly. Prior work (Agarwal 1997; Carroll et al. 1996; Ganco, Agarwal 2009; Klepper 2002a,b; Klepper, Simons 2000; Mitchell 1991) found that the advantage of diversifying entrants is persistent only in specific settings and typically tends to erode over time. We are aware of other specifics of SMEs. Revenue development was relatively easy to measure and it also describes business performance reasonably well. Revenue development, not revenue in a particular year, was chosen in order to observe company growth and to make numbers comparable. Considerations were that accounting only for revenue would most likely lead to biased results, since we would be comparing revenues of companies of different sizes. The company size might also correlate with the alignment fit of business and information strategies. Besides, net profit development might describe the performance even better, but companies are usually not too willing to share this information. The value might also be significantly influenced by the tax optimization rather than only by the actual performance. Moreover, in the case of loss, the fraction would include negative numbers, which cannot happen with revenue. Moreover, we are aware of a potential problem with endogeneity - i.e. good companies will both align strategies well and have good performance.

Of the 131 companies, 58 reported having an information strategy. The fact that only $44 \%$ of companies had an information strategy (after over a decade that the article titled "Information Systems Strategy: Long Overdue and Still Not Here" (M. L. Hatten, K. J. Hatten (1997) was published) may be surprising, but this percentage is comparable, e.g., to the situation in Slovak companies estimated in (Sudzina 2006).

Extrapolation methods assume that subjects who respond less readily are more similar to non-respondents (Pace 1939). "Less readily" means answering later, or those requiring more prodding to answer. Since we did not remind or urge respondents to reply, our "less readily" respondents are only late respondents; accordingly, we compared whether there was a significant difference between early and late respondents. Altogether, we considered the first 90 responses (who answered by the time we requested) to be early responses, the remaining 41 responses to be late. The results indicate that there is no significant difference in early and late respondents when it comes to percentage of compa- 
nies with information strategy, alignment, and revenue growth. To be more specific, for information strategy, $\mathrm{p}$-value $=0.280$; for alignment, $\mathrm{p}$-value $=0.718$; and for revenue development, $\mathrm{p}$-value $=0.174$. Although this does not prove that non-respondents would give the same answers, at least it does not suggest that they would differ significantly. All 58 companies, which answered that they have an information strategy, answered the question "How well is your corporate strategy and corporate structure aligned with the IT-strategy and IT-infrastructure?". They rated the perceived alignment on a Likert scale of $1-5$, where 1 stands for very bad and 5 for very good. The same wording of the question and the same scale were used e.g. in Bernroider, Hampel (2005). With the exception of five companies, respondents provided information on their revenue development over the years 2004-2006; thus, the effective sample size was 53 (58-5). The reason for taking into consideration the revenue development over a period of 3 years was to avoid the effects of internal factors (such as tactical decisions) and external factors (i.e., environment changes). The questionnaire contained the question "What has been the economic development of your organization over the years 2004-2006?". The possible answers were: 1) reduction in revenue, 2) stable (i.e., zero growth), 3) growth of $0-5 \%, 4)$ growth of 5-10\%, and 5) higher growth.

The distribution of the revenue development and alignment of business and information strategies is presented in Table 1. The median for the alignment of business and information strategies is 4 (i.e. good alignment), and the median for the revenue development is the fourth interval $(5-10 \%)$.

A similar research conducted in the Slovak Republic, which is described in Johansson, Sudzina (2009), has shown that the revenue development is higher for companies with very bad and bad alignment (1-2) than for companies with mediocre alignment (3), while it is also higher for companies with good alignment (4) than for companies with mediocre alignment (3). In other words, the relationship was, obviously, not linear, not even monotonic. If the relationship was at least approximately linear, it would make sense to use ordinary least squares regression in this article. If the relationship was at least monotonic, it would make sense to use probit regression in this article. But due to the nature of the relationship between the revenue development and the alignment observed in Slovak companies, we used multinomial logit regression in the first step. We treated both the company size and the alignment as categorical variables.

Table 1. Revenue development and alignment of business and information strategies

\begin{tabular}{lcccccc}
\hline Alignment $\backslash$ revenue development & Negative & $0 \%$ & $0-5 \%$ & $5-10 \%$ & $10+\%$ & Total \\
\hline $1-$ very bad alignment & 0 & 0 & 0 & 1 & 0 & 1 \\
\hline $2-$ bad alignment & 0 & 0 & 0 & 0 & 0 & 0 \\
\hline $3-$ mediocre alignment & 1 & 4 & 3 & 3 & 1 & 12 \\
\hline $4-$ good alignment & 2 & 2 & 6 & 9 & 12 & 31 \\
\hline $5-$ very good alignment & 1 & 1 & 0 & 2 & 5 & 9 \\
\hline Total & 4 & 7 & 9 & 15 & 18 & 53 \\
\hline
\end{tabular}


In the second step, we broke down exactly which levels of alignment led to specific revenue development levels. The issue of statistical power in information systems research has been known for at least 20 years, when Baroudi and Orlikowski (1989) estimated that information systems researchers typically have a $40 \%$ chance of not detecting the phenomenon under study, even though it, in fact, may exist. Our approach to this problem was to merge values of the two variables (i.e. of alignment and revenue), that is to decrease the number of groups being compared, and thus to increase the statistical power.

\section{Results}

The results of the multinomial logit regression indicate that the impact of the alignment on revenue development ( $\mathrm{p}$-value $=0.079$ ) is more significant than the impact of company size ( $p$-value $=0.404)$. As mentioned earlier, the research question is whether there is a significant impact of perceived alignment of information and business strategies, and company size on revenue development, using as powerful test as possible. Since company size is a control variable and the effect of company size is not significant, we leave it out as suggested by Carlson and Wu (2012). Given the nature of remaining variables, the chi-square test was the most suitable option. The only way to increase the power, given the test, was to decrease the number of values of the variable(s).

With regards to the values of revenue development, we used the idea behind Mood's median test (Mood 1954), i.e., to split the value into two groups of the same size. The median for the revenue development is the fourth interval (5-10\%). The closest possibility to having two groups of the same size was to merge companies with the revenue development lower than the fourth interval (i.e. 5-10\%) and higher and equal to the fourth interval (i.e. 5-10\%); i.e. into groups with lower than 5\% revenue development, and with higher or equal to $5 \%$ revenue development. If we, actually, followed the algorithm (i.e., to put values smaller and equal to the fourth interval (i.e. 5-10\%) into one group and values higher than the fourth interval (i.e. 5-10\%) into another; i.e. into groups with lower and equal to $10 \%$ revenue development, and with higher than $10 \%$ revenue development), we would end up with a split, which would lead to a larger difference in group sizes.

With regards to the values of the alignment between business and information strategies, although alignment of 1-3 could be tagged as "low to mediocre", we do not do so because there was only one observation on perceived alignment of value 1, none of value 2, and we are aware that as pointed out e.g., in Eckhardt et al. (2007) the relationship need not be monotonic by default. Moreover, a similar research in Slovak companies (Johansson, Sudzina 2009) has shown that the turnover development is higher for companies with very bad and bad alignment (1-2) than for companies with mediocre alignment (3), while it is also higher for companies with good alignment (4) than for companies with mediocre alignment (3). Thus, we rather refrain from assuming anything about the low alignment.

Since the described mergers of values formulated in a table of $2 \times 3$ did not yield a significant relationship, we opt for a table $2 \times 2$, which has the highest statistical power for chi-square, as presented in Table 2. 
Table 2. Revenue development and alignment of business and information strategies

\begin{tabular}{lccc}
\hline Alignment/revenue development & $<5 \%$ & $\geq 5 \%$ & Total \\
\hline Mediocre (3) & 8 & 4 & 12 \\
\hline High (4-5) & 12 & 28 & 40 \\
\hline Total & 20 & 32 & 52 \\
\hline
\end{tabular}

There is a significant relationship between the alignment of business and information strategies and revenue development $(\mathrm{p}$-value $=0.022)$. The link is positive - companies with high (i.e. good (4) - very good (5)) alignment are more likely to have revenue growth of at least $5 \%$.

On the other hand, it should be stressed that managers should not undergo the process of aligning business and information strategies if they cannot observe significant increase in their firm's performance. In other words, the alignment should not be a goal per se but seen only as a facilitator.

Another unintended observation is that the alignment between business and information strategies is rather high. About a decade ago Rosa (1998) and Luftman et al. (1999) pointed out that, given the importance and potential benefits of alignment, the number of organizations that successfully align their information strategy with business strategy is considerably small. One decade was probably enough for companies to understand the value that high alignment could bring about and they, therefore, learned how to achieve it.

\section{Conclusions and future research}

Our investigation of perceived alignment between business strategy, information strategy, and revenue growth shows that there is a significant relationship between alignment of business and information strategies and revenue growth in Slovenia. From this, it can be concluded that the positive link that, for instance, Tallon (2007) claims exists between alignment and performance, is supported; however, we do not find support for the counter argument that Renaud and Kalika (2008) claim about alignment and firms' performance.

As for future research, it is proposed that several comprehensive questions on particular aspects of alignment (such as the ones proposed by Khaiata and Zualkernan (2009)) be used, and that several people per company be surveyed. This could then lead to a lower evaluation of the alignment, which, in turn, might allow for the analysis of whether very bad alignment is also connected with a high revenue growth.

Future research could also account for the approach used for information strategy formulation and implementation, as described in Salmela and Spil (2002), since it could impact the actual alignment and possibly also business performance. There may be a difference between which school of thought companies implicitly use - information strategy supporting business strategy, synchronization of information and business strategies, 
convergence of information and business strategies, etc. Another possible approach is to investigate IT governance as a whole using dimensions defined by Novotny et al. (2012), one of which is the alignment. Novotny et al. (2012) identified four different operationalizations to measure alignment of business and information strategies.

\section{References}

Agarwal, R. 1997. Survival of firms over the product life cycle, Southern Economic Journal 63(3): 571-583. http://dx.doi.org/10.2307/1061095

Aldrich, H. 1979. Organizations and environments. Englewood Cliffs, NJ: Prentice-Hall.

Allen, D.; Wilson, T. 2003. Vertical trust/mistrust during information strategy formation, International Journal of Information Management 23(3): 223-237.

http://dx.doi.org/10.1016/S0268-4012(03)00026-4

Armstrong, J. S.; Overton, T. S. 1977. Estimating nonresponse bias in mail surveys, Journal of Marketing Research 14(3): 396-402. http://dx.doi.org/10.2307/3150783

Baroudi, J. J.; Orlikowski, W. J. 1989. The problem of statistical power in MIS research, MIS Quarterly 13(1): 87-106. http://dx.doi.org/10.2307/248704

Bernroider, E. W. N.; Hampel, A. 2005. Enterprise resource planning and IT governance in perspective: strategic planning and alignment, value delivery and controlling, in Fifth International Conference on Electronic Business (ICEB 2005), 5-9 December 2005, Hong Kong, China, 306-308.

Carlson, K. D.; Wu, J. 2012. The illusion of statistical control: control variable practice in management research, Organizational Research Methods 15(3): 413-435.

http://dx.doi.org/10.1177/1094428111428817

Carroll, G.; Bigelow, L.; Seidel, M.; Tsai, L. 1996. The fates of de novo and de alio producers in the American automobile industry: 1885-1981, Strategic Management Journal 17(special issue): $117-137$.

Chan, Y. E. 2002. Why haven't we mastered alignment? The importance of the informal organization structure, MIS Quarterly Executive 1(2): 97-112.

Chan, Y. E.; Reich, B. H. 2007. IT alignment: what have we learned?, Journal of Information Technology 22(4): 297-315. http://dx.doi.org/10.1057/palgrave.jit.2000109

Chan, Y. E.; Sabherwal, R.; Thatcher, J. B. 2006. Antecedents and outcomes of strategic IS alignment: an empirical investigation, IEEE Transactions on Engineering Management 51(1): 27-47. http://dx.doi.org/10.1109/TEM.2005.861804

Delina, R.; Tkáč, M. 2010. The impacts of specific ICT solutions on productivity, in IDIMT-2010: Information Technology - Human Values, Innovation and Economy: 18th Interdisciplinary Information Management Talks, 8-10 September 2010, Jindřichův Hradec, Czech Republic. Linz: SEA, 23-32.

Dess, G. G.; Beard, D. W. 1984. Dimensions of organizational task environments, Administrative Science Quarterly 29(1): 52-73.

Dorčák, P.; Delina, R. 2011. Vplyv elektronických marketingových podnikových riešení na ekonomickú výkonnost' [Impact of e-marketing services on economic performance], Ekonomický časopis 59(1): 44-58.

Eckhardt, A.; Pokorny, J.; Vojtas, P. 2007. A system recommending top-k objects for multiple users preferences, in IEEE International Conference on Fuzzy Systems, IEEE, 23-26 July 2007, London, 1101-1106.

European Commission. 2003. SME definition: recommendation 2003/361/EC regarding the SME definition. 
Ganco, M.; Agarwal, R. 2009. Performance differentials between diversifying entrants and entrepreneurial start-ups: a complexity approach, Academy of Management Review 34(2): 228-252. http://dx.doi.org/10.5465/AMR.2009.36982618

Hatten, M. L.; Hatten, K. J. 1997. Information systems strategy: long overdue and still not here, Long Range Planning 30(2): 254-266. http://dx.doi.org/10.1016/S0024-6301(96)00117-3

Henderson, J. C.; Venkatraman, N. 1993. Strategic alignment: leveraging information technology for transforming organizations, IBM Systems Journal 32(1): 4-16.

http://dx.doi.org/10.1147/sj.382.0472

Johansson, B.; Sudzina, F. 2009. Can both good and bad alignment of business and information strategies lead to high business performance?, in The 12th International Business Information Management Association Conference - Creating Global Economies through Innovation and Knowledge Management: Theory \& Practice, 29-30 June 2009, Kuala Lumpur, Malaysia. International Business Information Management Association (IBIMA). 1382-1387.

Johnson, A. M.; Lederer, A. L. 2005. The effect of communication frequency and channel richness on the convergence between chief executive and chief information officers, Journal of Management Information Systems 22(2): 227-252.

Kearns, G. S.; Sabherwal, R. 2006. Strategic alignment between business and information technology: a knowledge-based view of behaviors, outcome, and consequences, Journal of Management Information Systems 23(3): 129-162. http://dx.doi.org/10.2753/MIS0742-1222230306

Khaiata, M.; Zualkernan, I. A. 2009. A simple instrument to measure IT-business alignment maturity, Information Systems Management 26(2): 138-152. http://dx.doi.org/10.1080/10580530902797524

Klepper, S. 2002a. Firm survival and the evolution of oligopoly, RAND Journal of Economics 33(1): 37-61. http://dx.doi.org/10.2307/2696374

Klepper, S. 2002b. The capabilities of new firms and the evolution of the US automobile industry, Industrial and Corporate Change 11(4): 645-665. http://dx.doi.org/10.1093/icc/11.4.645

Klepper, S.; Simons, K. L. 2000. Dominance by birthright: entry of prior radio procedures and competitive ramifications in the U.S. television receiver industry, Strategic Management Journal 21(10): 997-1016.

http://dx.doi.org/10.1002/1097-0266(200010/11)21:10/11<997::AID-SMJ134>3.0.CO;2-O

Leidner, D. E.; Lo, J.; Preston, D. 2011. An empirical investigation of the relationship of IS strategy with firm performance, Journal of Strategic Information Systems 20(4): 419-437. http://dx.doi.org/10.1016/j.jsis.2011.09.001

Luftman, J.; Kempaiah, R.; Nash, E. 2006. Key issues for IT executives 2005, MIS Quarterly Executive 5(2): 81-101.

Luftman, J.; Kempaiah, R.; Rigoni, E. H. 2009. Key issues for IT executives 2008, MIS Quarterly Executive 8(3): 151-159.

Luftman, J.; Papp, R.; Brier, T. 1999. Enablers and inhibitors of business-IT alignment, Communications of AIS 1(11): 1-33.

Marchand, M.; Raymond, L. 2008. Researching performance measurement systems: an information systems perspective, International Journal of Operations \& Production Management 28(7): 663-686. http://dx.doi.org/10.1108/01443570810881802

Mitchell, W. 1991. Dual clocks: entry order influences on incumbent and newcomer market share and survival when specialized assets retain their value, Strategic Management Journal 12(2): 85-100. http://dx.doi.org/10.1002/smj.4250120202

Mood, A. M. 1954. On the asymptotic efficiency of certain nonparametric two-sample tests, Annals of Mathematical Statistics 25(3): 514-522. http://dx.doi.org/10.1214/aoms/1177728719

Novotny, A.; Bernroider, E. W. N.; Koch, S. 2012. Dimensions and operationalisations of IT governance: a literature review and meta-case study, in International Conference on Information Resource Management, 21-23 May 2012, Vienna, Austria. Vienna: The University of Aukland and Wirtschaftsuniversität Wien. 
Pace, C. R. 1939. Factors influencing questionnaire returns from former university students, Journal of Applied Psychology 23(3): 388-397. http://dx.doi.org/10.1037/h0063286

Papp, R. 1999. Business-IT alignment: productivity paradox payoff?, Industrial Management \& Data Systems 99(8): 367-373. http://dx.doi.org/10.1108/02635579910301810

Plomp, M. G. A.; Batenburg, R. 2009. Procurement maturity, alignment and performance: a Dutch hospital case comparison, in 22nd Bled eConference on eEnablement - Facilitating an Open, Effective and Representative eSociety, 14-17 June 2009, Bled, Slovenia. Faculty of Organizational Sciences, University of Maribor, Bled. 203-219.

Prahalad, C. K.; Krishnan, M. S. 2002. The dynamic synchronization of strategy and information technology, MIT Sloan Management Review 43(4): 24-33.

Reich, B. H.; Benbasat, I. 2000. Factors that influence the social dimension of alignment between business and information technology objectives, MIS Quarterly 24(1): 81-113.

http://dx.doi.org/10.2307/3250980

Renaud, A.; Kalika, M. 2008. Prospective strategic behaviour and IS coalignment, impact on performance, an alternative perspective, in Proceedings of the Mediterranean Conference on Information Systems (MCIS 2008), 23-26 October 2008, Hammamet, Tunisia.

Rosa, J. 1998. CIOs challenged by disparate goals, Computer Reseller News, 7 December, 1998: 43.

Salmela, H.; Spil, T. A. M. 2002. Dynamic and emergent information systems strategy formulation and implementation, International Journal of Information Management 22(6): 441-460. http://dx.doi.org/10.1016/S0268-4012(02)00034-8

Simonsen, J. 2007. Involving top management in IT projects, Communications of ACM 50(8): 53-58. http://dx.doi.org/10.1145/1278201.1278206

Singh, S. N.; Woo, C. 2009. Investigating business-IT alignment through multi-disciplinary goal concepts, Requirements Engineering 14(3): 177-207.

http://dx.doi.org/10.1007/s00766-009-0081-0

Smits, M.; Fairchild, A.; Ribbers, P.; Milis, K.; van Geel, E. 2009. Assessing strategic alignment to improve IT effectiveness, in 22nd Bled eConference on eEnablement - Facilitating an Open, Effective and Representative eSociety, 14-17 June 2009, Bled, Slovenia. Faculty of Organizational Sciences, University of Maribor, Bled. 426-439.

Sudzina, F. 2006. Information strategy in Slovak companies in the period of 2003-2006, Management 11(42): 52-66.

Tallon, P. P. 2007. A process-oriented perspective on the alignment of information technology and business strategy, Journal of Management Information Systems 24(3): 227-268.

http://dx.doi.org/10.2753/MIS0742-1222240308

Tallon, P. P.; Kraemer, K. L.; Gurbaxani, V. 2001. Executives'perceptions of the business value of information technology: a process-oriented approach, Working Paper \#ITR-148. Center for Research on Information Technology and Organizations, Graduate School of Management, University of California.

Valorinta, M. 2011. IT alignment and the boundaries of the IT function, Journal of Information Technology 26(1): 46-59. http://dx.doi.org/10.1057/jit.2010.28

Vitale, M. R.; Ives, B.; Beath, C. M. 1986. Linking information technology and corporate strategy: an organizational view, in Proceedings of the 7th International Conference on Information System, December 1986, San Diego, CA. Association for Information Technology Trust. 265-276. 
Björn JOHANSSON is an Associate Professor in information systems at the School of Economics and Management, Lund University, Sweden. He received his PhD in Information Systems Development from the Department of Management \& Engineering at Linköping University, Sweden in 2007. He was involved in the 3rd Generation Enterprise Resource Planning - Strategic Software for Increased Globalization (3gERP.org) research project funded by the Danish National Advanced Technology Foundation. He is a member of the IFIP Working Groups IFIP 8.6 and IFIP 8.9, and the Swedish National Research School Management and IT (MIT).

František SUDZINA is an Associate Professor in business economics at the Department of Business and Management, and inter-faculty department located at the Faculty of Social Sciences and the Faculty of Engineering and Science, Aalborg University, Denmark. He received his PhD in Sectoral and Intersectoral Economics from the University of Economics Bratislava, Slovakia in 2003. He was involved in the 3rd Generation Enterprise Resource Planning - Strategic Software for Increased Globalization (3gERP.org) research project funded by the Danish National Advanced Technology Foundation. He is a member of numerous programme committees for international conferences, and is a member of editorial boards for several journals.

Andreja PUCIHAR is an Assistant Professor in e-business and management of information systems at the Faculty of Organizational Sciences, the University of Maribor, Slovenia. She received her PhD in the MIS field from the University of Maribor, Slovenia in 2002. Since 1995, she has been involved in eCenter and its several research and project activities. She is a head of eMarkets Laboratory and contact person for Living laboratory for research fields of eMarkets, eSMEs and eGovernment. She is involved in several national and EU projects focusing new e-business models, social media, living labs and open innovation. She is a conference chair of the Bled eConference (BledConference.org). 